\title{
Morphology of lateral line canals in Neotropical freshwater stingrays (Chondrichthyes: Potamotrygonidae) from Negro River, Brazilian Amazon
}

\author{
Akemi Shibuya ${ }^{1}$, Jansen Zuanon ${ }^{1}$, Maria Lúcia G. de Araújo ${ }^{2}$ and Sho Tanaka ${ }^{3}$
}

The relationship between the distribution of the lateral line canals and their functionality has not been well examined in elasmobranchs, especially among Neotropical freshwater stingrays of the family Potamotrygonidae. The spatial distribution of the canals and their tubules and the quantification of the neuromasts were analyzed in preserved specimens of Potamotrygon motoro, P. orbignyi, Potamotrygon sp. "cururu", and Paratrygon aiereba from the middle Negro River, Amazonas, Brazil. The hyomandibular, infraorbital, posterior lateral line, mandibular, nasal and supraorbital canals were characterized and their pores and neuromasts quantified. The ventral canals are known to facilitate the accurate localization of prey items under the body, and our results indicate that the dorsal canals may be employed in identifying the presence of predators or potential prey positioned above the stingray's body. The presence of non-pored canals in the ventral region may be compensated by the high concentration of neuromasts found in the same area, which possibly allow the accurate detection of mechanical stimuli. The concentration of non-pored canals near the mouth indicates their importance in locating and capturing prey buried in the bottom substrate, possibly aided by the presence of vesicles of Savi.

A relação entre a distribuição dos canais da linha lateral e a sua funcionalidade é pouco conhecida para os elasmobrânquios, especialmente para as raias neotropicais da família Potamotrygonidae. A distribuição espacial dos canais e seus túbulos e a quantificação dos neuromastos foram analisadas em exemplares preservados das raias Potamotrygon motoro, P. orbignyi, Potamotrygon sp. "cururu” e Paratrygon aiereba, provenientes do médio rio Negro, Amazonas, Brasil. Foram identificados os canais hiomandibular, infra-orbital, linha lateral posterior, mandibular, nasal e supra-orbital, e os poros e neuromastos de cada um foram quantificados. Nossos resultados mostram que os canais dorsais podem ter a função de identificar a presença de predadores ou presas posicionadas acima do corpo da raia, enquanto os canais ventrais provavelmente permitem uma localização precisa da posição de presas sob o corpo. A existência de canais sem poros na região ventral pode estar relacionada com a alta concentração de neuromastos, que compensaria a falta de contato direto dos neuromastos com o meio externo na detecção de estímulos mecânicos. A concentração dos canais sem poros na proximidade da boca indica sua importância para a localização e captura de presas enterradas no substrato, possivelmente auxiliadas pela presença das vesículas de Savi.

Key words: Feeding behavior, Mechanosensory, Neuromast, Paratrygon, Potamotrygon.

\section{Introduction}

The lateral line system occurs in all aquatic amphibians and fishes, and represents an important detector of water movements near the skin surface (Maruska \& Tricas, 1998; Bleckmann \& Hofmann, 1999; Peach \& Marshall, 2000; Maruska, 2001; Peach, 2003). Different types of lateral line organs are found in chondrichthyans, although their functions are still not well understood (Barry \& Bennett, 1989; Maruska, 2001).
A comprehensive study carried out by Chu \& Wen (1979) examined the morphological distribution of the lateral line system in 73 species of sharks, skates, rays and chimaeras. Coombs et al. (1989) subsequently described the biological, physiological and evolutionary aspects of these canals in amphibians, teleosts and elasmobranchs. An investigation of the role of the lateral line system by Montgomery \& Skipworth (1997) tested the detection of weak water movements in Dasyatis brevicaudata. Maruska \& Tricas (1998) analyzed the distribution of lateral line canals in $D$.

${ }^{1}$ Coordenação de Pesquisas em Biologia Aquática, Instituto Nacional de Pesquisas da Amazônia, INPA. Av. André Araújo, 2936, Aleixo, 69060-001 Manaus, Amazonas, Brazil. akemi_shibuya@yahoo.com.br, zuanon@inpa.gov.br

${ }^{2}$ Instituto de Ciências Biológicas, Universidade Federal do Amazonas, UFAM. Av. Gen. Rodrigo Octávio Jordão Ramos, 3000, Coroado I, 69077-000 Manaus, Amazonas, Brazil. mlpotamotrygon@gmail.com

${ }^{3}$ Tokai University, School of Marine Science and Technology. 3-20-1 Orido, 424-8610, Shimizu, Shizuoka, Japan. sho@scc.u-tokai.ac.jp 
sabina, and Maruska (2001) demonstrated that the lateral line system has an important role in aquatic environments, and compared the distributions of lateral line canals among five elasmobranch species with similar habits. The latter author also proposed the mechanotactile hypothesis for the nonpored canals found in batoid species, which was later tested and confirmed by Maruska \& Tricas (2004).

Furthermore, the distribution of mechanoreceptors may be related to the habitat occupied by each species, their activity levels, and their phylogenetic relationships (Maruska \& Tricas, 1998; Maruska, 2001; Motta \& Wilga, 2001). There is a general lack of information about the role of lateral line system in many batoid groups, including its morphology, distribution and function in Neotropical freshwater stingrays (Potamotrygonidae). Garman (1888) observed the occurrence of vesicles of Savi in potamotrygonid stingrays, and found that the morphology and location of these mechanoreceptors were similar to those of dasyatid rays. Lovejoy (1996) analyzed the phylogeny of myliobatoid rays and provided a brief description of the lateral line system on the ventral surface of potamotrygonids.

More information on the mechanosensory system is clearly needed in freshwater stingrays, especially in light of their foraging habits on different types of substrate (over litter banks, sandy and muddy bottoms) (Araújo et al., 2004) and the low visibility in river environments, which may impair prey location. Mechanoreceptors seem to be essential to prey capture in batoid species due to their limited ability to determine prey positions under their bodies using visual clues. Additionally, stingrays seem to prey on many individuals of the same prey type, suggesting the capacity to locate and forage on abundant prey sources on the river bottom (Montgomery \& Skipworth, 1997).

The present study describes the distribution of lateral line canals in four species of potamotrygonid stingrays (Potamotrygon motoro, Potamotrygon orbignyi, Potamotrygon sp. "cururu", and Paratrygon aiereba). To help interpreting the role of the morphology and distribution of lateral line system in the foraging behavior and feeding habits of these stingrays, the pores on the dorsal and ventral surfaces were quantified. Neuromasts were also quantified on both body surfaces of Potamotrygon motoro and $P$. orbignyi, and their densities were compared considering the available information on the feeding habits of these batoid species.

\section{Material and Methods}

Specimens of Potamotrygon motoro, Potamotrygon orbignyi, Potamotrygon sp. "cururu" (an undescribed species) and Paratrygon aiereba were obtained from the middle Negro River, Amazonas State, Brazil (Fig. 1). Voucher specimens are catalogued at Instituto Nacional de Pesquisas da Amazônia, Manaus, Brazil; Potamotrygon motoro, INPA 27091; P. orbignyi, INPA 27088; Potamotrygon sp. "cururu", INPA 34960; Paratrygon aiereba, INPA 34959. All analyzed specimens were preserved in $10 \%$ formalin solution and conserved in $75 \%$ ethanol. The skin from the dorsal and ventral surfaces of all specimens was removed to examine the lateral line canals. The terminology used here follows Chu \& Wen (1979) and Maruska (2001): nasal canal (NS), hyomandibular (HYO), infraorbital (IO), mandibular (MAN), posterior lateral line (PLL), and supraorbital (SO) (Fig. 2).

Schematic diagrams of the location of lateral line canals were drawn from dissected specimens with the aid of a stereoscopic microscope. Tubules, branched tubules and pores were quantified on the left side of the body (assuming bilateral symmetry). Vesicles of Savi and connections between ventral and dorsal canals were identified by injecting $0.5 \%$ toluidine blue solution into each canal (Maruska, 2001).

The distribution and quantification of neuromasts were only analyzed in Potamotrygon motoro and P. orbignyi, with the dorsal and ventral surfaces of body being divided in following sections (Fig. 2): Dorsal surface - anterior (from rostrum to posterior region of the eye), central (posterior region of the eye to the posterior lateral line canal loop, in the scapular region), and posterior (from scapular region to the distal margin of the body); and Ventral surface - anterior (from rostrum to the anterior region of first branchial slit), central (from the first gill slit to the fifth gill slit), and posterior (from the fifth branchial slit to the distal margin of the body).

The lateral line canals were opened under a stereoscopic microscope and $0.5 \%$ toluidine blue solution was injected into them to quantify the neuromasts in each part of the body. Neuromasts were counted on both the dorsal and ventral surfaces of body in only juvenile specimens, due to their easier manipulation. Five specimens of $P$. motoro and seven of $P$. orbignyi were examined and the neuromasts enclosed in the lateral line canals on both the dorsal and ventral surfaces were counted. Neuromast density (ND) was calculated according to the following equation: $\mathrm{ND}=\mathrm{NN} / \mathrm{L}_{\text {canal }}$, where $\mathrm{NN}$ is the number of neuromasts and $\mathrm{L}_{\text {canal }}$ is the canal length $(\mathrm{cm})$. Canal length was measured by following the canal's trajectory with a string and measuring its extension with a ruler (in centimeters).

Neuromasts were quantified on the dorsal and ventral body surfaces. The ratio (RT) between these two surfaces was calculated as: $\mathrm{RT}=\mathrm{NNv} / \mathrm{NNd}$, where $\mathrm{NNv}$ and $\mathrm{NNd}$ are the total number of neuromasts on the ventral and dorsal surfaces respectively. To calculate the neuromast density (ND) on the anterior (A), central (C) and posterior (P) parts of body, we formulated the following equation: $\mathrm{ND}_{\mathrm{pb}}=\mathrm{NN}_{\mathrm{pb}} / \mathrm{L}_{\mathrm{pb}}$, where $\mathrm{NN}_{\mathrm{pb}}$ is the total number of neuromasts on any given part of the body (anterior, central or posterior) and $\mathrm{L}_{\mathrm{pb}}$ is the total canal length of each part of the body.

Mean, standard deviation, minimum and maximum number of neuromasts were presented as mean $\pm \mathrm{SD}$; min-max. The numbers of pores and vesicles of Savi, as well as the numbers of neuromasts and their densities among the different species were compared using Student's t-test ( $\alpha=$ 0.05) (Zar, 1996). 


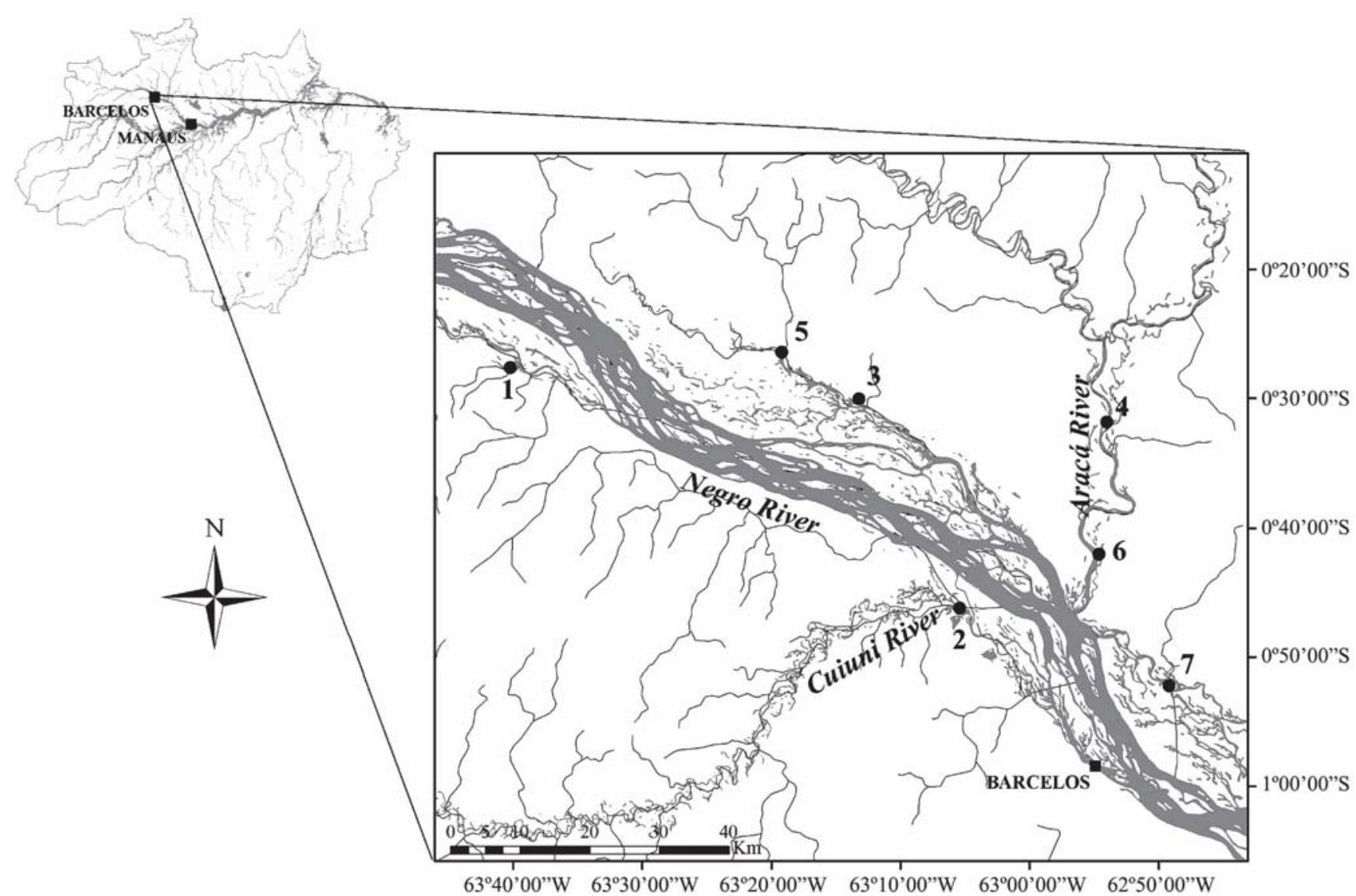

Fig. 1. Sampling sites of Potamotrygon motoro, P. orbignyi, Potamotrygon sp. "cururu" and Paratrygon aiereba, in the middle Negro River, Barcelos, Amazonas State, Brazil. 1) Arirahá River; 2) Cuiuni River; 3) Daraquá stream; 4) Demeni River; 5) Itu River; 6) Maqui Lake; 7) Zamula stream.

The terms used in the current study followed Maruska (2001). "Neuromast" refers to the mechanoreceptor found in the lateral line canal that is covered by a gelatinous cupulae. "Tubule" is the extension of the main canal, lacking neuromasts and terminating in pores. The term "pore" refers to the tubule aperture on the skin surface that serves to maintain neuromasts canals in contact with the external environment.

\section{Results}

Six specimens of Potamotrygon motoro, eight of $P$. orbignyi, two of Potamotrygon sp. "cururu" and one of Paratrygon aiereba were analyzed in the present study. Potamotrygon motoro, P. orbignyi, and Potamotrygon sp. "cururu" had similar distributions of lateral line canals, and were distinguishable only by their numbers of pores (Figs. $3 \mathrm{a}-\mathrm{c})$. Due to their similarity, the organization of lateral line canals on the dorsal and ventral surfaces of the Potamotrygon species were described together, but separate from Paratrygon aiereba.

Dorsal body surface of Potamotrygon species. The dorsal surface canals consist of hyomandibular, infraorbital, supraorbital and posterior lateral line canals terminating in pores (Figs. 3a-c). The hyomandibular canal extends to near the pectoral fin edge, between the rostral, and the scapular loop and is joined to the posterior lateral line canal. In the rostrum section, the hyomandibular canal extends to the eye on the midline, and penetrates through the body to join the hyomandibular canal on the ventral surface (Figs. 3a-c, marked by squares). The hyomandibular canal on the dorsal surface has long radial tubules that terminate in pores. Tubules of the hyomandibular canal in P. motoro and Potamotrygon sp. "cururu" terminate in one or two pores, while in $P$. orbignyi they terminate in up to eight pores.

The infraorbital canal is located on the lateral margin of the eye. It joins the supraorbital canal by a short extension located between the eye and the spiracle. The infraorbital canal penetrates through the body and connects to the same canal on the ventral surface near the rostrum (Figs. 3a-c, marked by triangles). The supraorbital canal extends caudally from the rostrum and connects to the anterior region of the posterior lateral line canal. The supraorbital canal has short branches just dorsal to the eye, and terminates in a single pore.

The posterior lateral line canal is located on the dorsal midline of the body, and reaches the tip of the tail. This canal is connected to supraorbital canal just posterior to the head, and it has a short postorbital connection joining the canals 


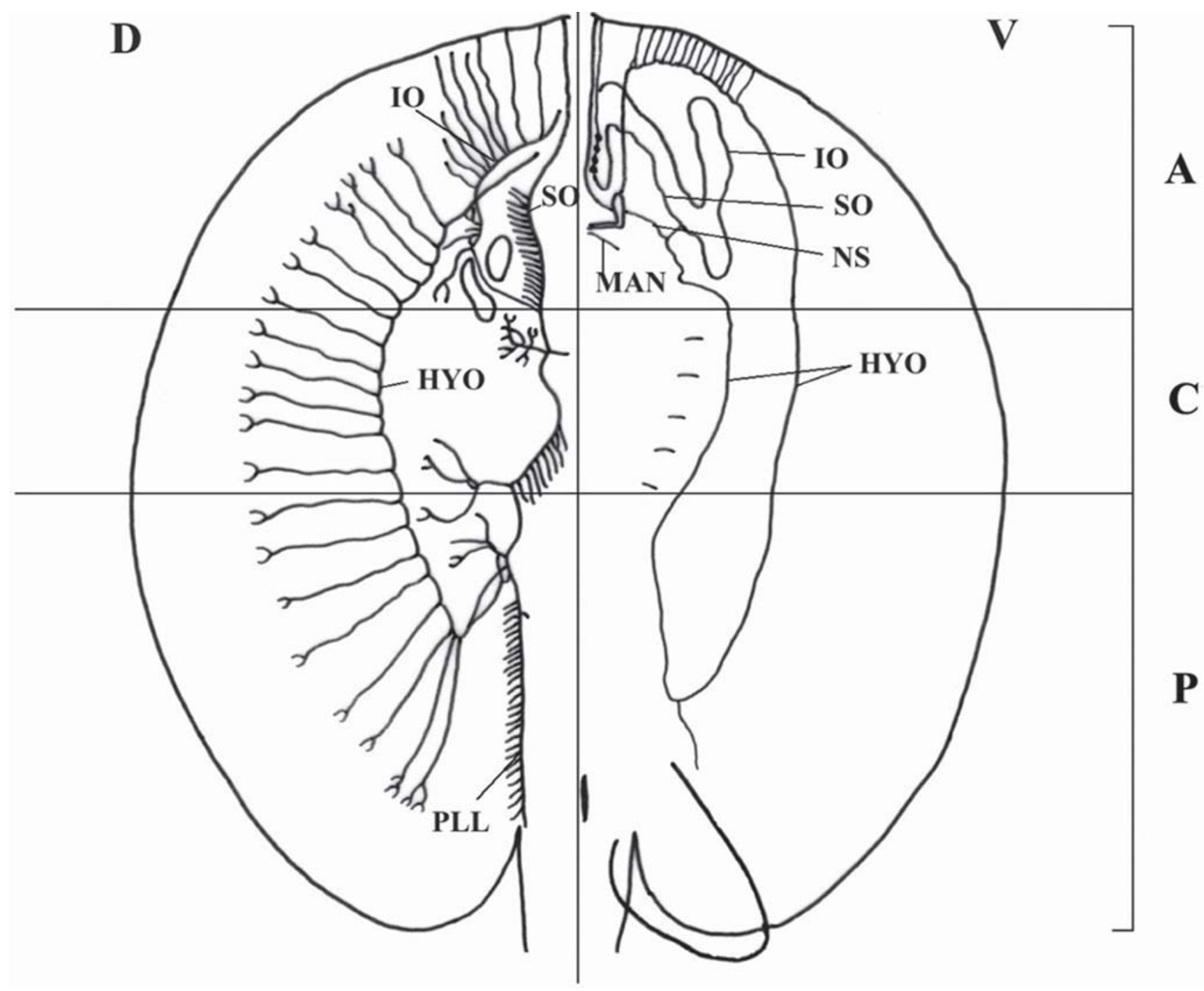

Fig. 2. Lateral line canals on the dorsal (D) and ventral (V) surfaces, divided in three sections to quantify neuromasts in Potamotrygon motoro and P. orbignyi. A) anterior; C) central, and P) posterior. HYO) hyomandibular canal; IO) infraorbital canal; MAN) mandibular canal; NS) nasal canal; PLL) posterior lateral line canal; SO) supraorbital canal.

from the left and right sides on the dorsal surface. The posterior lateral line canal is connected to the hyomandibular canal and has straight tubules that terminate in single pores posterior to the scapular loop.

Ventral body surface of the Potamotrygon species. The lateral line canals on the ventral surface of body present pored and non-pored canals, with hyomandibular, infraorbital, supraorbital, nasal and mandibular canals and vesicles of Savi. The pored canals include the hyomandibular canal that has tubules terminating in single pores and concentrated on the rostrum, with only one tubule on the posterior portion of that canal; the infraorbital, supraorbital and nasal canals are connected to the hyomandibular canal near the mouth.

Infraorbital and supraorbital canals are concentrated around the mouth, nostrils, and the anterior region of the branchial slits. The infraorbital canal reaches the midline of the rostrum, penetrates through the body, and connects to the same canal on the dorsal surface. The supraorbital canal is modified to as series of vesicles of Savi on the midline of rostrum. Like the infraorbital canal, the supraorbital canal penetrated through the body on the midline of the rostrum and joins to the dorsal supraorbital canal. The vesicles of Savi are arranged in a single longitudinal row on each side of body. The nasal canal is parallel to the vesicles of Savi and extends under the nostril and connects to the hyomandibular, infraorbital and supraorbital canals. The nasal canal has a connection between canals on the left and right sides of body just anterior to the mouth. The non-pored mandibular canal is located posterior to the lower jaw.

Dorsal body surface in Paratrygon aiereba. The description of the distribution of lateral line canals in Paratrygon aiereba is based on only one specimen (Fig. 3d). All canals of the 

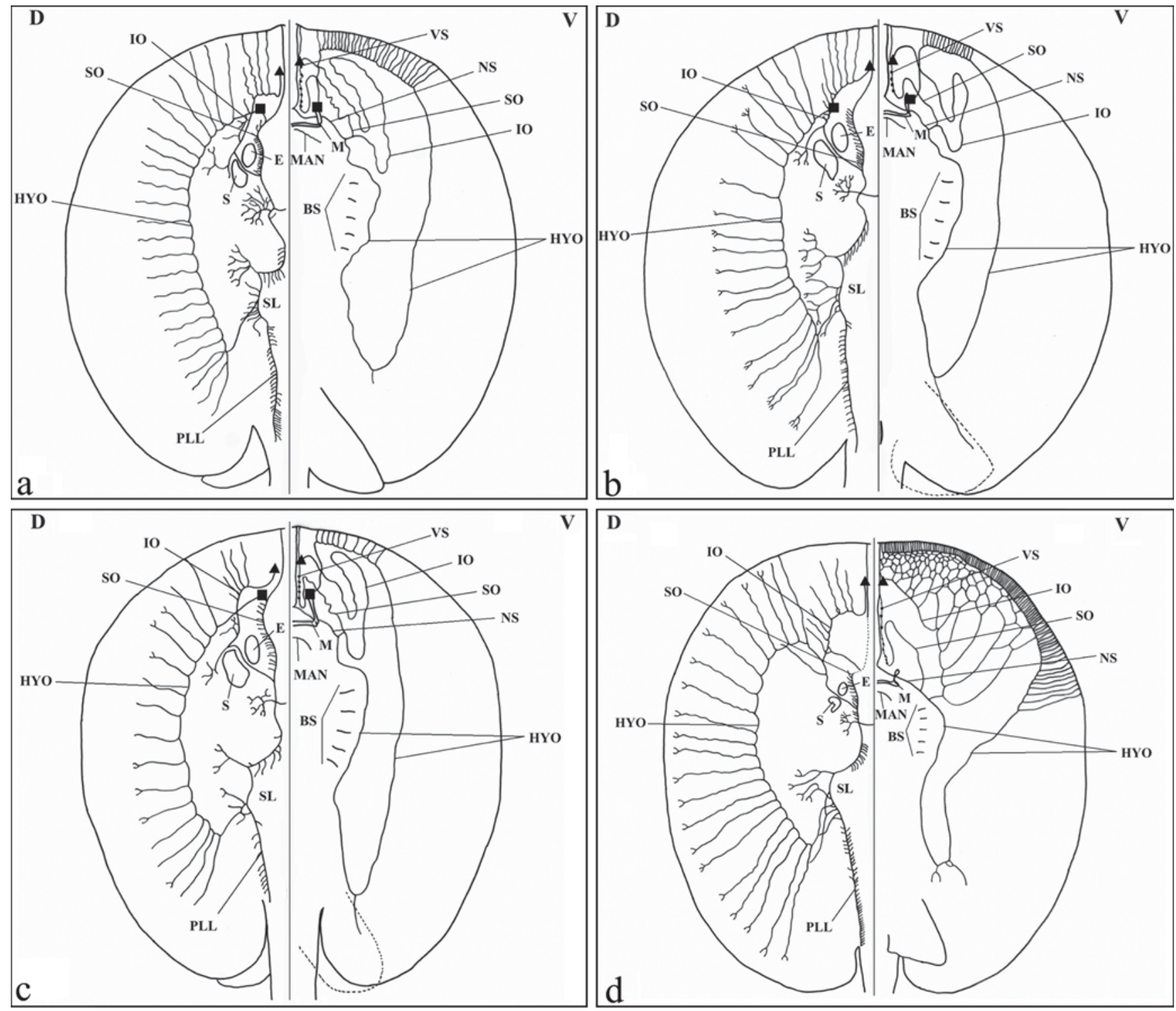

Fig. 3. Distribution of the lateral line canals in Potamotrygon motoro (a), P. orbignyi (b), Potamotrygon sp. "cururu" (c), and Paratrygon aiereba (d) and their connections between the dorsal (D) and ventral (V) surfaces. BS) branchial slits; E) eye; HYO) hyomandibular canal; IO) infraorbital canal; M) mouth; MAN) mandibular canal; NS) nasal canal; PLL) posterior lateral line canal; S) spiracle; SL) scapular loop; SO) supraorbital canal; VS) vesicles of Savi; square) connection of the hyomandibular canal; triangle) connection of the infraorbital canal. Potamotrygon motoro: DW $=18.5 \mathrm{~cm} ;$ P. orbignyi: DW $=26.7 \mathrm{~cm}$; Potamotrygon sp. "cururu": DW = $18.7 \mathrm{~cm}$; and Paratrygon aiereba: DW $=18.9 \mathrm{~cm}$. DW = disc width.

lateral line system on the dorsal surface had tubules terminating in pores. The hyomandibular canal extends along the body margin and terminates in up to three pores. Different from the Potamotrygon species, there is a connection between the anterior sections of the infraorbital to hyomandibular canals in $P$. aiereba. Connections between the hyomandibular canal from the dorsal and ventral surfaces were not found.

Infraorbital and supraorbital canals are connected to each other by a short branch located between the eye and the spiracle. The supraorbital canal extends from the rostrum, submerges under the conjunctive tissue (Fig. 3d, discontinued row) in front of the cranium, and emerges at the cranium. This canal continues laterally to the fontanel and then joins the posterior lateral line canal. The posterior part of the hyomandibular canal joins to the posterior lateral line canal on the scapular loop. Any connection between the dorsal and ventral surfaces is found only in the infraorbital canal in P. aiereba (Fig. 3d, marked by triangles).

Ventral body surface in Paratrygon aiereba. The hyomandibular canal on the ventral surface of $P$. aiereba has connections with the infraorbital, nasal and supraorbital canals. The hyomandibular canal extends laterally to the branchial slits and has two tubules that terminate in three 
pores near the pelvic fin. This canal has a series of tubules that extend laterally from the rostrum to the branchial slits, totaling 114 pores on each side of the body.

The anterior portion of the infraorbital canal has webshaped branches connected to the hyomandibular canal. The infraorbital canal penetrates the body and connects to the infraorbital canal on the midline of the rostrum on its dorsal surface. The anterior portion of the supraorbital canal has nine vesicles of Savi in longitudinal row on each side of the body.

The nasal canal is placed parallel to the row of vesicles of Savi, penetrates under the nostril, and then connects to the junction of the hyomandibular, infraorbital and supraorbital canals. The nasal canal has a connection between the canals from the left and right side of the body anterior to the mouth. The mandibular canal is short and non-pored.

Quantification of lateral line pores and vesicles of Savi. The features of the lateral line system are summarized in Table 1. The numbers of pores of the hyomandibular canal on the dorsal surface of Potamotrygon orbignyi was significantly higher than seen in P. motoro $\left(\mathrm{U}_{0.05 ; 8 ; 6}=0 ; \mathrm{p}<0.001\right)$, whereas Paratrygon aiereba presented a higher value compared to Potamotrygon species (not tested). The numbers of vesicles of Savi in $P$. motoro were significantly higher than in $P$. orbignyi $\left(\mathrm{U}_{0.05 ; 8 ; 6}=2 ; \mathrm{p}=0.002\right)$.

Distribution of neuromasts in Potamotrygon motoro and $\boldsymbol{P}$. orbignyi. The neuromasts are arranged into longitudinal rows in the interior of the canals and the tubules lack neuromasts. Potamotrygon motoro had about twice as many neuromasts on its ventral surface (ventral: $\mathrm{x}=513, \pm 28$; dorsal: $\mathrm{x}=270, \pm 9$ ) as on its dorsal surface. Potamotrygon orbignyi also had a higher number of neuromasts on ventral than on dorsal

Table 1. Numbers (min - max) of vesicles of Savi (VS), pores in each pored canals, and pores per tubule $(\mathrm{p} / \mathrm{t})$ on the dorsal and ventral body surfaces. IO) infraorbital, HYO-D) dorsal hyomandibular, HYO-V) ventral hyomandibular, PLL) posterior lateral line, and SO) supraorbital.

\begin{tabular}{|c|c|c|c|c|c|c|}
\hline Species & VS & $\begin{array}{c}\text { HYO-D } \\
(\mathrm{p} / \mathrm{t})\end{array}$ & HYO-V & $\mathrm{IO}$ & PLL & SO \\
\hline $\begin{array}{l}\text { Potamotrygon } \\
\text { motoro }(\mathrm{n}=6)\end{array}$ & $7-11$ & $18-24(1-2)$ & $15-26$ & $13-19$ & $48-83$ & $14-28$ \\
\hline $\begin{array}{l}\text { Potamotrygon } \\
\text { orbignyi }(\mathrm{n}=8)\end{array}$ & $4-7$ & $31-49(1-8)$ & $10-24$ & $11-18$ & $51-76$ & $13-20$ \\
\hline $\begin{array}{l}\text { Potamotrygon sp. } \\
\text { "cururu" }(\mathrm{n}=2)\end{array}$ & $4-5$ & $16-23(1-2)$ & $7-10$ & $18-19$ & $33-37$ & $6-12$ \\
\hline $\begin{array}{l}\text { Paratrygon } \\
\text { aiereba }(\mathrm{n}=1)\end{array}$ & 9 & $41(1-3)$ & 114 & 8 & 76 & 14 \\
\hline
\end{tabular}

surface (ventral: $x=434, \pm 11$; dorsal: $x=284, \pm 14$ ) (Table 2 ).

The numbers of neuromasts and their densities on the three body parts (anterior, central and posterior) of both the dorsal and ventral surfaces are summarized in Table 3 . The pores are about six times more numerous on the dorsal than on the ventral surface in $P$. motoro (ventral: $118 \pm 15.8$; 106139; dorsal: $19 \pm 3.9 ; 15-26 ; \mathrm{n}=6$ ) and about nine times more numerous on the dorsal surface in $P$. orbignyi (ventral: $133 \pm 13.6$; 112-149; dorsal: $16 \pm 4.0 ; 13-24 ; \mathrm{n}=8$ ).

The number of neuromasts on the ventral surface was significantly higher in $P$. motoro $(\mathrm{t}=-6.43, \mathrm{n}=5, \mathrm{p}=0.003)$ than in P. orbignyi $(\mathrm{t}=-11.07, \mathrm{n}=7, \mathrm{p}<0.001)$. However, the numbers of neuromasts on the dorsal $v s$. ventral surfaces between these species did not show significant differences (dorsal: $\mathrm{t}=-0.09, \mathrm{p}=0.92$; ventral: $\mathrm{t}=2.09, \mathrm{p}=0.06$ ). A comparison among the different body portions of $P$. motoro indicated that the numbers of neuromasts on the anterior portion were significantly higher than those observed in the central and posterior portions of the dorsal and ventral surfaces (Table 4).

Potamotrygon orbignyi had higher numbers of neuromasts on the anterior and posterior regions of the dorsal surface as compared to the central region, but there was no significant difference between the central and posterior regions. The anterior section also had higher numbers of neuromasts than central and posterior regions on its ventral surface (Table 4).

The densities of neuromasts were also significantly higher on the anterior than on the central and posterior regions of the dorsal and ventral surfaces for both Potamotrygon motoro and P. orbignyi (Table 5). Only the number of neuromasts on the anterior section of the ventral surface of $P$. motoro was significantly higher than that of $P$. orbignyi (Table 6$)$.

\section{Discussion}

According to Hueter et al. (2004), the effectiveness of sense organs for prey detection is related to two factors: their sensitivity to minimum stimuli, and their accuracy in detecting the type and the origin of the stimuli they receive. Batoids have a flattened body, dorsal eyes and a ventral mouth features that suggest an important role for non-visual sense organs such as olfactory, electroreceptor, and lateral line mechanosensory systems in prey detection and capture. Elasmobranchs have several types of mechanoreceptors, and their functions and response properties vary depending on their shape and their location on the body (Maruska, 2001).

Table 2. Mean number of neuromasts (NN) on the ventral (V) and dorsal (D) surfaces, and their ratio (RT); and for each canal in Potamotrygon motoro and P. orbignyi. HYO) hyomandibular canal; IO) infraorbital canal; SO) supraorbital canal; MAN) mandibular canal; NS) nasal canal; PLL) posterior lateral line canal.

\begin{tabular}{lcccccccccc}
\hline & NN (Total) & & \multicolumn{3}{c}{ NN (Ventral) } & \multicolumn{2}{c}{ NN (Dorsal) } \\
\hline Species & V/D (RT) & NS & IO & HYO & MAN & SO & IO & HYO & PLL & SO \\
\hline P. motoro & $513.0 / 270.8(1.9)$ & 31.8 & 160.0 & 262.0 & 15.6 & 43.6 & 20.6 & 90.6 & 126.2 & 73.4 \\
P. orbignyi & $434.1 / 284.8(1.5)$ & 27.9 & 102.6 & 246.3 & 11.6 & 45.8 & 25.6 & 110.3 & 115.3 & 67.1 \\
\hline
\end{tabular}


Table 3. Mean numbers of neuromasts and their density per centimeter of canal length $(C L)$ in the three body sections $(\mathrm{A}=$ anterior, $\mathrm{C}=$ central, and $\mathrm{P}=$ posterior $)$ on the ventral and dorsal surfaces in Potamotrygon motoro and $P$. orbignyi.

\begin{tabular}{lcccccc}
\hline & \multicolumn{3}{c}{ Ventral (CL) } & \multicolumn{3}{c}{ Dorsal (CL) } \\
\hline Species & $\mathrm{A}$ & $\mathrm{C}$ & $\mathrm{P}$ & $\mathrm{A}$ & $\mathrm{C}$ & $\mathrm{P}$ \\
\hline \multirow{2}{*}{ P. motoro } & 377.2 & 65.0 & 70.8 & 97.0 & 85.0 & 88.8 \\
& $(8.4)$ & $(7.9)$ & $(7.2)$ & $(6.2)$ & $(6.4)$ & $(6.5)$ \\
P. orbignyi & 293.7 & 63.1 & 77.3 & 91.7 & 99.4 & 93.7 \\
& $(8.1)$ & $(7.0)$ & $(7.4)$ & $(6.1)$ & $(6.4)$ & $(6.2)$ \\
\hline
\end{tabular}

Lateral line canals on the dorsal body surface. The distributions of lateral line canals on the dorsal surface of Potamotrygon motoro, P. orbignyi and Potamotrygon sp. "cururu" appear to be similar, except for the numbers of branches of the hyomandibular canal. No significant differences between the numbers of pores on the infraorbital, supraorbital and posterior lateral line canals were observed among these species.

According to Maruska \& Tricas $(1998,2004)$ and Maruska (2001), pored canals on the dorsal surface may function in identifying water movements generated by predators (defense), prey items (feeding), and con-specifics (e. g., schooling and mating behavior). Most potamotrygonid rays feed on benthic organisms (Lasso et al., 1996; Lonardoni et al., 2006) such as insect larvae and crustaceans. However, the occurrence of teleost fishes (Cichlidae and Engraulididae) in the stomach contents of $P$. motoro and Paratrygon aiereba (Shibuya et al., 2009) indicate an important role of pored canals in prey detection. This detection probably occurs by the sensing of water movements generated by these prey items. Stingrays forage predominantly at night, when visual stimuli are probably of minimal importance in prey detection. Although the mentioned teleost fishes have diurnal habits, they may have been preyed upon at night when resting near the river bottom. In this case, a stationary, resting prey could be initially detected by olfactory stimuli; then, after being caught and kept under the ray's body, mechanoreceptors could be used to precisely locate the prey under the body and to guide it to its mouth.

Comparisons between Potamotrygon motoro and $P$. orbignyi indicated that the numbers of pores on the

Table 4. Comparisons of the numbers of neuromasts among the different body sections ( $\mathrm{A}=$ anterior, $\mathrm{C}=$ central, and $\mathrm{P}=$ posterior) on both the dorsal and ventral surfaces of Potamotrygon motoro and P. orbignyi. Significant results marked with an asterisk $(*=$ higher in $\mathrm{A} ; * *=$ higher in $\mathrm{P})$.

\begin{tabular}{lccccc}
\hline Surfaces & Body sections & \multicolumn{2}{c}{ P. motoro } & \multicolumn{2}{c}{ P. orbignyi } \\
\hline \multirow{3}{*}{ Dorsal } & & $\mathrm{t}$ & $\mathrm{p}$ & $\mathrm{t}$ & $\mathrm{p}$ \\
\cline { 2 - 6 } & $\mathrm{A}-\mathrm{C}$ & 4.57 & $0.01^{*}$ & 2.52 & $0.04^{*}$ \\
& $\mathrm{~A}-\mathrm{P}$ & 3.39 & $0.02^{*}$ & 0.08 & 0.93 \\
& $\mathrm{C}-\mathrm{P}$ & -1.80 & 0.14 & -5.58 & $<0.01^{* *}$ \\
\hline Ventral & $\mathrm{A}-\mathrm{C}$ & 22.76 & $<0.01^{*}$ & 21.11 & $<0.01^{*}$ \\
& $\mathrm{~A}-\mathrm{P}$ & 22.83 & $<0.01^{*}$ & 16.91 & $<0.01^{*}$ \\
& $\mathrm{C}-\mathrm{P}$ & 0.36 & 0.73 & -2.36 & 0.05 \\
\hline
\end{tabular}

Table 5. Comparisons of the densities of neuromasts among the different body sections $(\mathrm{A}=$ anterior, $\mathrm{C}=$ central, and $\mathrm{P}=$ posterior $)$ on both the dorsal and ventral surfaces of Potamotrygon motoro and $P$. orbignyi. Significant results marked with an asterisk $(*=$ higher in $\mathrm{A} ; * *=$ higher in $\mathrm{P})$.

\begin{tabular}{lccccc}
\hline Surfaces & Body sections & \multicolumn{2}{c}{ P. motoro } & \multicolumn{2}{c}{ P. orbignyi } \\
\hline \multirow{3}{*}{ Dorsal } & & $\mathrm{t}$ & $\mathrm{p}$ & $\mathrm{t}$ & $\mathrm{p}$ \\
\cline { 2 - 6 } & $\mathrm{A}-\mathrm{C}$ & -3.22 & $0.03^{*}$ & -3.35 & $0.01^{*}$ \\
& $\mathrm{~A}-\mathrm{P}$ & 3.61 & $0.02^{*}$ & 2.95 & $0.02^{*}$ \\
& $\mathrm{C}-\mathrm{P}$ & 6.18 & $<0.01^{* *}$ & 9.78 & $<0.01^{* *}$ \\
\hline Ventral & $\mathrm{A}-\mathrm{C}$ & 19.33 & $<0.01^{*}$ & 10.01 & $<0.01^{*}$ \\
& $\mathrm{~A}-\mathrm{P}$ & 18.87 & $<0.01^{*}$ & 9.48 & $<0.01^{*}$ \\
& $\mathrm{C}-\mathrm{P}$ & -2.01 & 0.11 & -0.61 & 0.56 \\
\hline
\end{tabular}

hyomandibular canal were significantly higher in the latter species. Potamotrygon orbignyi occurs mainly associated with sandy beaches, whereas $P$. motoro show more generalized habits and inhabits floodplain forests ("igapó"), sandy and muddy beaches, litter banks and river channels (M. L. G. Araújo field observation). The high number of pores on the dorsal surface of $P$. orbignyi may reflect its habit of lying buried in the bottom substrate in the highly exposed habitats of sandy beaches and its need to detect water movements generated by predators, prey items or unknown objects above its body (as was observed for Dasyatis sabina by Maruska \& Tricas, 1998).

Chu \& Wen (1979) presented a comprehensive study of the distribution of lateral line canals in chondrichthyans species, analyzing 73 species of sharks, skates and rays. The organization of the tubules in the dorsal canals may be related to variations in the receptive stimulus field for each species. However, according to the observation of Chu \& Wen (1979) and Maruska (2001), the number of tubules may also be restricted according to phylogeny and this may be the case of derived batoids such as the Myliobatiformes. So, a more comprehensive analysis of the distribution of lateral line canals among Potamotrygonidae species is necessary to verify if the differences observed in our study reflect intrafamilial phylogenetic trends.

Lateral line canals on the ventral body surface. Batoid species show higher morphological variations in the lateral line canals on their ventral surfaces as compared to their dorsal surfaces.

Table 6. Comparisons of the numbers of neuromasts and their densities on the different body sections $(\mathrm{A}=$ anterior, $\mathrm{C}=$ central, and $\mathrm{P}=$ posterior) on both the dorsal and ventral surfaces of Potamotrygon motoro and P. orbignyi. Significant results marked with an asterisk ( $*$ higher in $P$. motoro).

\begin{tabular}{lccccc}
\hline Surfaces & Body sections & \multicolumn{2}{c}{ Number of neuromasts } & \multicolumn{2}{c}{ Density } \\
\hline \multirow{3}{*}{ Dorsal } & & $\mathrm{t}$ & $\mathrm{p}$ & $\mathrm{t}$ & $\mathrm{p}$ \\
\cline { 3 - 6 } & $\mathrm{A}$ & 0.77 & 0.45 & 0.35 & 0.73 \\
& $\mathrm{C}$ & -0.44 & 0.66 & 1.87 & 0.11 \\
& $\mathrm{P}$ & -2.07 & 0.06 & 0.86 & 0.42 \\
\hline Ventral & $\mathrm{A}$ & 3.81 & $<0.01^{*}$ & 1.37 & 0.22 \\
& $\mathrm{C}$ & 0.23 & 0.81 & 1.64 & 0.16 \\
& $\mathrm{P}$ & -1.47 & 0.16 & 0.58 & 0.58 \\
\hline
\end{tabular}


Ventral canals lack pores (except for the hyomandibular canal, which was composed of tubules that end in single pores in all of the species analyzed here). The high concentration of pores on anterior section of the hyomandibular canal in Potamotrygon species suggests an important role in prey detection during foraging (especially during substrate excavation in search for buried prey).

The infraorbital, mandibular, nasal and supraorbital canals do not have pores, and their functions were unknown until the formulation of the "mechanotactile hypothesis" by Maruska \& Tricas (1998). According to these authors, the lack of contact with the external environment suggests that these non-pored canals are not used to detect water movements. This hypothesis was tested by Maruska \& Tricas (2004) using neurophysiological experiments and have confirmed that the non-pored canals of the lateral line system on the ventral body surface can detect tactile stimuli generated by the contact with prey.

The infraorbital canals in Potamotrygon motoro, $P$. orbignyi and Potamotrygon sp. "cururu" show an anterior loop after their junctions with the nasal and supraorbital canals. According to Lovejoy (1996), this loop in the infraorbital canal in Potamotrygon can be considered a derived condition for this genus. In spite of the fact that this loop may have an inherited phylogenetic origin, it may have an important function as it increases the canal length and its location near the mouth and nostrils may allow increased surface contact with the mechanoreceptive field of the lateral line canals on the ventral surface. This feature may improve the accuracy of prey detection during foraging in the variety of complex substrates present in Neotropical freshwater environments.

According to Maruska \& Tricas (1998), the pores along the hyomandibular canal on the ventral surface of Dasyatis sabina reduce the noise caused by excavation during foraging, while the tactile sensitive non-pored canals is used for prey detection. Potamotrygon orbignyi uses its pectoral fins to excavate the substrate (M.L.G. Araújo and J. Zuanon field observations), and prey detection may be performed by either pored or non-pored canals on the ventral surface, which deserves more detailed studies.

The ventral canals in the single studied specimen of Paratrygon aiereba have a distinct morphology as compared to Potamotrygon species. The infraorbital canal comprises a web-like complex of branches connected to hyomandibular and nasal canals that penetrate through the body and joins the same infraorbital canal on the dorsal surface. These ramified branches and the complexity of the non-pored canals probably contribute to increase the sensitivity of mechanotactile receptive field on the ventral surface around the mouth. These characteristics possibly provide compensation the large disk size attained by $P$. aiereba and the more posterior position of its mouth, which could hinder the proper location of prey.

Maruska (2001) proposed that the complexity of the lateral line canal was higher in derived species such as in Myliobatiformes. This contradicts the phylogenetic hypotheses of Lovejoy (1996) and Carvalho et al. (2004), in which Paratrygon is basal to both Potamotrygon and Plesiotrygon. A more detailed examination of the distribution of lateral line canals may help to explain whether any correlation between phylogeny, ecology and body size occurs in batoid groups.

According to Maruska \& Tricas (1998), pored canals are stimulated by water movements during excavation or while the animal is buried in the substrate. Pores of the hyomandibular canal on the ventral surface may also be used to detect water displacement by prey items. Observations in captivity (Shibuya, 2009) indicated that potamotrygonid rays lift their rostrum close to their prey before capturing it, indicating the use of pored canals on the ventral surface to detect water movements generated by prey activity.

Some features of the lateral line canals probably increase the sensitivity of the tactile receptive field for prey detection, such as the anterior loop of the infraorbital canal on the ventral surface (present in Potamotrygon motoro, P. orbignyi and Potamotrygon sp. "cururu") and the web-like complex of the same canal in Paratrygon aiereba. During prey capture, individuals of Potamotrygon motoro curve their bodies and assume a convex shape around the prey to reduce its chances of escaping. The ray then uses its own body to immobilize the prey by pressing it against the substrate. Similar feeding behavior was observed in Urobatis halleri, Rhinobatos lentiginosus and Dasyatis chrysonota (Babel, 1967; Wilga \& Motta, 1998; Ebert \& Cowley, 2003), indicating the importance of non-pored mechanoreceptors for tactile sensitivity while hunting.

Vesicles of Savi were found on ventral surfaces of all of the species analyzed. These vesicles are used as the main mechanism of prey detection by species of Torpediniformes due to the lack of lateral line canals on the ventral surface of these batoids (Maruska, 2001). Vesicles of Savi occurred in low numbers on the midline section of the body near the rostrum in the stingrays analyzed. The arrangement of vesicles and the location of the mandibular canal near the mouth suggest that these mechanoreceptors act in the final guidance movements of prey capture, helping to reposition the mouth to seize prey (Maruska \& Tricas, 1998; Maruska, 2001). Although this function remains unproven, they almost certainly have a tactile function (Garman, 1892; Barry \& Bennett, 1989; Maruska, 2001; Hueter et al., 2004).

Neuromast distribution. The densities of neuromasts in Potamotrygon motoro and P. orbignyi were similar to those reported by Maruska \& Tricas (1998) for D. sabina. The dorsal surface has more pores than the ventral surface; the opposite being observed for the numbers of neuromasts. Potamotrygon motoro and $P$. orbignyi consume prey items that are usually buried ( $P$. motoro feeds especially on crustaceans, while a predominance of burying insect larvae was observed in the diet of $P$. orbignyi; see Shibuya et al., 2009); however the ratio between the number of neuromasts on the dorsal and ventral surfaces was higher in Potamotrygon motoro than in P. orbignyi. 
According to Maruska (2001), the lack of external contact by non-pored canals on the ventral body surface may be offset by the high densities of neuromasts. Ventral canals have morphological differences that suggest higher sensitivity, with thinner walls and larger diameters than the dorsal canals, features that may facilitate fluid displacement over the cupulae of hair cells and thus increase their tactile sensitivity (Maruska \& Tricas, 1998; 2004).

The sizes of the neuromasts varied according to their location inside the canals. Canal sections with wave-like arrangements have small neuromasts as compared to straight or slightly curved sections. Comparisons of the anterior, central and posterior sections of the ventral surfaces of $P$. motoro and $P$. orbignyi showed high densities of neuromasts on the anterior section near the mouth. This distribution probably increases the tactile receptive field of the non-pored canals during feeding activities.

Additionally, the lateral line system of elasmobranchs has free neuromasts (pit organs) (Peach \& Marshall, 2000; Maruska, 2001). Peach \& Marshall (2000) and Peach (2003) demonstrated the importance of free neuromasts for prey detection under low light conditions as well as their chemoreceptor functions (Katsuki et al., 1969). Free neuromasts were not examined in the present study, and a more complete knowledge of their function may provide valuable additional information about the biology and behavior of potamotrygonid species in the typically low visibility environments of rivers in the Amazon basin.

The distribution of lateral line canals was analyzed in only four Potamotrygonidae species; however our results indicate that these mechanoreceptors represent important systems associated with the habits of these batoids. Ventral canals may not be directly related to the type of food consumed by each species, but these canals appear to aid in detecting buried prey and striking during the final stages of foraging behavior.

\section{Acknowledgements}

The authors would like to thank Sidinéia Amadio and Marcelo Rocha for valuable comments on the manuscript. The first author thanks the Japan International Cooperation Agency (JICA) for financial support and technical trainee fellowship. AS and JZ thank the Conselho Nacional de Desenvolvimento Científico e Tecnológico (CNPq) for the doctoral and productivity (process \# 307464/2009-1) grants respectively.

\section{Literature Cited}

Araújo, M. L. G., P. Charvet-Almeida, M. P. Almeida \& H. Pereira. 2004. Freshwater stingrays (Potamotrygonidae): status, conservation and management challenges. Information document AC 20 info 08: 1-6.

Babel, J. S. 1967. Reproduction, life history and ecology of the round stingrays, Urolophus halleri Cooper. Department of Fish and Game. Fish Bulletin 137, 104p.
Barry, M. A. \& M. V. L. Bennett. 1989. Specialized lateral line receptor systems in elasmobranchs: The spiracular organs and Savi vesicles. Pp. 591-606. In: Coombs, S., P. Gorner \& H. Munz. (Eds.). The mechanosensory lateral line - Neurobiology and evolution. Springer-Verlag, New York.

Bleckmann, H. \& M. H. Hofmann. 1999. Special senses. Pp. 300328. In: Hamlett, W. C. (Ed.). Sharks skates and rays, the biology of elasmobranch fishes. The John Hopkins University Press. Baltimore, Maryland.

Carvalho, M. R., J. G. Maisey \& L. Grande. 2004. Freshwater stingrays of the Green River formation of Wyoming (Early Eocene), with description of a new genus and species and an analysis of its phylogenetic relationships (Chondrichthyes: Myliobatiformes). Bulletin of the American Museum of Natural History, 284: 1-136.

Chu, Y. T. \& M. C. Wen. 1979. A study of the lateral-line canals system and that of Lorenzini ampullae and tubules of elasmobranchiate fishes of China. Monograph of Fishes of China. Academic press, Shangai, 132p.

Compagno, L. J. V. 2005. Checklist of living Chondrichthyes. Pp. 503-548. In: Hamlett, W. C. (Ed.). Reproductive biology and phylogeny of Chondrichthyes: sharks, batoids and chimaeras. Science Publishers, Enfield.

Coombs, S., P. Gorner \& H. Münz. 1989. The mechanosensory lateral line - Neurobiology and evolution. New York. SpringerVerlag, $724 \mathrm{p}$.

Ebert, D. A. \& P. D. Cowley. 2003. Diet, feeding behaviour and habitat utilization of the blue stingray Dasyatis chrysonota (Smith, 1828) in South African waters. Marine and Freshwater Research, 54:957-965.

Garman, S. 1888. On the lateral canal system of Selachia and Holocephala. Bulletin of the Museum of Comparative Zoology, 17: $57-119$

Garman, S. 1892. The Savi vesicles. Science, 474(19): 128.

Hueter, R. E., D. A. Mann, K. P. Maruska, J. A. Sisneros \& L. S. Demski. 2004. Sensory biology of Elasmobranchs. Pp. 325368. In: Carrier, J. C., J. A. Musick \& M. R. Heithaus. (Eds.). Biology of Sharks and Their Relatives. CRC Press, Boca Raton.

Katsuki, Y., K. Yanagisawa, A. L. Tester \& J. I. Kendall. 1969. Shark pit organs: response to chemicals. Science, 163: 405407.

Lasso, C. A., A. B. Rial \& O. Lasso-Alcalá. 1996. Notes on the biology of the freshwater stingrays Paratrygon aiereba (Müller \& Henle, 1841) and Potamotrygon orbignyi (Castelnau, 1855) (Chondrichthyes: Potamotrygonidae) in the Venezuelan llanos. Aqua, Journal of Ichthyology and Aquatic Biology, 2(3): 39-52.

Lonardoni, A. P., E. Goulart, E. F. Oliveira \& M. C. F. Abelha. 2006. Hábitos alimentares e sobreposição trófica das raias Potamotrygon falkineri e Potamotrygon motoro (Chondrichthyes, Potamotrygonidae) na planície alagável do alto rio Paraná, Brasil. Acta Scientiarum Biological Sciences, 3(28): 195-202.

Lovejoy, N. R. 1996. Systematic of Myliobatoid elasmobranchs: with emphasis of phylogeny and historical biogeography of Neotropical stingrays (Potamotrygonidae: Rajiformes). Zoological Journal of Linnean Society, 117: 207-257.

Maruska, K. P. 2001. Morphology of the mechanosensory lateral line system in elasmobranch fishes: ecological and behavioral considerations. Environmental Biology of Fishes, 60: 47-75. 
Maruska, K. P. \& T. C. Tricas. 1998. Morphology of the mechanosensory lateral line system in the Atlantic stingray, Dasyatis sabina: the mechanotactile hypothesis. Journal of Morphology, 238: 1-22.

Maruska, K. P. \& T. C. Tricas. 2004. Test of mechanotactile hypothesis: neuromast morphology and response dynamics of mechanosensory lateral line primary afferents in the stingray. The Journal of Experimental Biology, 207: 3463-3476.

Montgomery, J. \& E. Skipworth. 1997. Detection of weak water jets by the short-tailed stingrays Dasyatis brevicaudata (Pisces: Dasyatidae). Copeia, 1997(4): 881-883.

Motta, P. J. \& C. D. Wilga. 2001. Advances in the study of feeding mechanisms, mechanics, and behaviors of sharks. Environmental Biology of Fishes, 20: 131-156.

Peach, M. B. \& N. J. Marshall. 2000. The pit organs of elasmobranchs: a review. Philosophical Transactions of the Royal Society London B, 355: 1131-1134.

Peach, M. B. 2003. Inter- and Intraspecific variation in the distribution and number of pit organs (free neuromasts) of sharks and rays. Journal of Morphology, 256: 89-102.

Shibuya, A. 2009. Morfologia funcional dos mecanismos de alimentação em raias Myliobatoidei, com ênfase em espécies de Potamotrygonidae do médio rio Negro. Unpublished Ph.D. Dissertation. Instituto Nacional de Pesquisas da Amazônia, Manaus, 138p.

Shibuya, A., M. L. G. de Araújo \& J. A. S. Zuanon. 2009. Analysis of stomach contents of freshwater stingrays (Elasmobranchii: Potamotrygonidae) from the middle Negro River, Amazonas, Brazil. Pan-American Journal of Aquatic Sciences, 4(4): 466465.

Wilga, C. D. \& P. J. Motta. 1998. Feeding mechanism of the Atlantic guitarfish Rhinobatos lentiginosus: modulation of kinematics and motor activity. The Journal of Experimental Biology, 2001:3167-3184.

Zar, J. H. 1996. Biostatistical analysis. Third Edition. New Jersey. Prentice Hall, 662p. 